\title{
O esporte no capitalismo tardio: imbricações entre cultura esportiva, economia e mercado
}

Sport in late capitalism: implications between sports culture, economy and market

Nadson Santana Reis

Faculdade de Educação Física, Universidade de Brasilia-UNB, Brasil

nadsonsr@hotmail.com

Vitor Húngaro

Faculdade de Educação Física Universidade de Brasilia-UNB, Brasil

Pedro Fernando Avalone de Athayde

Faculdade de Educação Física, Universidade de Brasilia-UNB, Brasil

Fernando Mascarenhas

Faculdade de Educação Física, Universidade de Brasilia-UNB, Brasil

\section{Resumo:}

Esse texto consubstancia um esforço teórico-conceitual de localizar a cultura - de modo mais geral - e o esporte - de maneira mais específica - no arcabouço da produção capitalista contemporânea. Para tanto, buscou-se refletir sobre o desenvolvimento da cultura no âmbito do capitalismo tardio com atenção para a aproximação entre cultura, economia e mercado. Isso com a finalidade de compreender as transformações que, nessa quadra histórica, atravessam o esporte moderno. Assim, as considerações apontam para os processos de integração entre economia de mercado e cultura de massa. O que têm levado, sobretudo no campo esportivo, à produção de um conjunto de mercadorias (commodities culturais) que passou a interagir com vários setores produtivos do mundo capitalista que, não obstante, delas precisam para viabilizar acúmulos e gerar lucros.

Palavras-chave: Cultura, Esporte, Economia, Capitalismo tardio.

\section{Abstract:}

This text embodies a theoretical and conceptual effort to locate culture - more generally - and sport - more specifically - within the framework of contemporary capitalist production. Therefore, we sought to reflect on the development of culture in the context of late capitalism with attention to the approximation between culture, economy and market. This is done in order to understand the transformations that, in this historical court, go through modern sport. Thus, the considerations point to the processes of integration between market economy and mass culture. This has led, especially in the sports field, to the production of a set of commodities (cultural commodities) that have come to interact with various productive sectors of the capitalist world, which nevertheless need them to make accumulations and generate possible profits.

KEYWORDS: Culture, Sport, Economy, Late capitalism.

\section{INTRODUÇÃo}

O aprofundamento do capitalismo como modo de produção e forma particular de organização da vida social vem promovendo, em escala global, um conjunto de transformações econômicas, sociais, políticas e

\section{Recepción: 07 Mayo 2020 | Aprobación: 19 Septiembre 2020 | Publicación: 30 Septiembre 2020}

Cita sugerida: Reis, N. S., Húngaro, V., Athayde, P. F. A. y Mascarenhas, F. (2020). O esporte no capitalismo tardio: imbricações entre cultura esportiva, economia e mercado. Educación Física y Ciencia, 22(3), e143. https://doi.org/10.24215/23142561e143 
culturais (Harvey, 1993; Jameson, 1996; Netto, 1996; Hobsbawm, 1997; Ianni, 1997) que, invariavelmente, alteram e/ou redesenham valores, costumes, ideias, tradições, modos e maneiras de produzir e perceber a vida social.

Tal processo - em curso e em movimento -, apesar das tensões, dos enfrentamentos, das resistências e dos reveses, generaliza-se e enraíza-se como tendência global, afetando deliberada e detidamente o conjunto da vida social, incidindo diretamente nas necessidades sociais (Netto, 1996) e na trama cotidiana que está no centro do acontecer histórico, respondendo pela "essência" da substância social (Heller, 2004) sem a qual o "[...] econômico não consegue continuar a se implantar e expandir" (Jameson, 2001, p. 60).

Apreender esses processos, torná-los inteligíveis e, por assim dizer, compreender seus fluxos, caminhos e lógicas de comportamento é, pois, o desafio de nosso tempo. O que, nas palavras de Harvey (2011), é fundamental para se entender as condições em que vivemos.

Assim, imbuído nesse desafio está a necessidade de compreender o que tem sido a cultura ${ }^{1}$ inserida nesse contexto e nessas dinâmicas. E, mais especificamente, o que tem sido o esporte no presente histórico. Uma empreitada que implica atenção à manifestação e expressão do contraditório, do diverso e do dissonante. Isso porque a cultura e, particularmente, o esporte, assim como outras manifestaçóes culturais, conjugam determinaçóes sociais, políticas e econômicas de natureza ambígua e contraditória que, pela complexidade, não podem ser negligenciadas.

Desse modo, refletir sobre a cultura e, individualmente, sobre o esporte - no atual estágio de desenvolvimento - é tarefa importante que impõe a necessidade de identificar mudanças, decifrar continuidades, reconhecer rupturas e diversidades, bem como desvelar desigualdades.

Nesse escopo, esse texto intenta discutir e problematizar sobre a aproximação e imbricação entre a cultura e dentro dela o esporte, o mercado e a economia no âmbito do capitalismo tardio. Para tanto, sua organização envolve o debate sobre o desenvolvimento da cultura no capitalismo tardio e, como um desdobramento, a discussão sobre o esporte, a economia e o mercado. Isso porque o esporte, enquanto resultado da produção cultural, está imerso e circunscrito nesse contexto, constituindo, na atualidade, num dos segmentos que mais crescem na área da mídia e do entretenimento (Kearney, 2003), ocupando, de tal modo, lugar de destaque no mundo dos negócios.

\section{O DESENVOLVIMENTO DA CULTURA NO CAPITALismo TARDiO}

O processo de expansão, aprofundamento e dilatação do capital - verificado, sobretudo, a partir da década de 1970 - implicou em um conjunto de ações coordenadas que, não obstante, requereu um movimento análogo, equivalente e paralelo na cultura. Isso porque a pluralidade de padróes de vida, de objetos e hábitos de consumo obstaculiza, em última instância, sua expansão e seu aprofundamento (Castellani Filho, 2013). Por outro lado, a unificação internacional dos projetos ideológicos voltados à construção do consenso dos sistemas políticos de controle e repressão acompanha, também, a urgência pela homogeneização da economia (Canclini, 1983). Assim, a construção de referências para uma cultura global é, pois, ambição e condição para a dilatação requerida pelo grande capital (Gonçalves, 1997). Desse modo, não se pode pensar o desenvolvimento da cultura apartado de uma determinada forma de produção material da vida social.

Nesse sentido, é fundamental ter claro que a cultura (superestrutura) não representa um momento apartado do modo de produção (estrutura). As manifestações culturais constituem, nessa direção, um espaço e tempo de incorporação de valores, ideologias e práticas sociais que permitem sustentar, avalizar e, também, contrariar a lógica do capital (Portelli, 1977; Simionatto, 2003).

Foi com base nesse entendimento que Gramsci (2011), a partir da análise do americanismo e fordismo, demonstrou as particularidades que o capitalismo assumiu nos Estados Unidos após a eclosão da crise de 1929. Para o autor, ocorreu o estabelecimento de uma nova morfologia capitalista que não era apenas econômica, mas também política e ideológica. Assim, Gramsci (2011) demostrou que para uma determinada forma de produção há que existir elementos correspondentes no contexto da cultura. Mesmo porque, na 
concepção do autor, é na esfera político-ideológica, ou seja, no âmbito da superestrutura, que se trava - em última instância - a batalha decisiva entre as classes sociais.

Dentro desse escopo, Jameson (1996), examinando a lógica cultural do capitalismo tardio ${ }^{2}$ - numa referência clara a Mandel (1982) -, argumenta que a lógica cultural contemporânea se tornou integrada à produção de mercadoria em geral. Em sua avaliação, “[...] nosso presente histórico é caracterizado precisamente pela fusão entre cultura e economia. A cultura não é mais um domínio onde negamos os efeitos ou nos refugiamos do capital, mas é sua mais evidente expressão” (Jameson, 2001, p. 09).

A esfera da cultura, para ele, se expandiu de forma a coincidir com a sociedade de consumo. Nesse sentido, o cultural já não se limita às formas anteriores, tradicionais ou experimentais, mas é consumido a cada momento da vida cotidiana, seja nas compras, nas atividades profissionais, nas várias formas de lazer televisuais, na produção para o mercado e no consumo (Jameson, 2001).

Nessa direção, os bens culturais cingem a base e superestrutura, produzindo significados e gerando lucros ${ }^{3}$. Isso porque, conforme o próprio Jameson (2001), o capitalismo tardio depende, para seu bom funcionamento, de uma lógica cultural, de uma sociedade de imagens voltada para o consumo. A cultura é, então, campo de treinamento onde se aprende as regras fundamentais do jogo contemporâneo - o jogo do consumo.

De maneira sintética, o autor assegura que a produção e o consumo cultural de massa - no âmbito da globalização e inscrito no contexto das novas tecnologias da informação - são, majoritariamente, produtos profundamente econômicos e totalmente integrados em seu sistema generalizado de mercantilização tais quais as demais áreas produtivas do capitalismo tardio.

As assertivas desenvolvidas por Anderson (1999) corroboram com esse entendimento. Para Anderson, a cultura expandiu-se a ponto de se tornar praticamente coextensiva à própria economia. Isso, não apenas como base sintomática de algumas das maiores indústrias do mundo, mas de modo muito mais profundo, mesmo porque todo objeto material ou serviço imaterial se transforma, de forma inseparável, uma marca trabalhável, ou produto vendável.

Harvey (1993, p. 148) assevera que esse movimento tem relações claras com o modelo de acumulação flexível ${ }^{4}$ implantada depois da crise de 1970. Para ele, esse modelo de acumulação foi acompanhado por um tipo de consumo, atento "[...] às modas fugazes e pela mobilização de todos os artifícios de indução de necessidades e de transformação cultural que isso implica”. Assim, a estética estável do modernismo fordista deu lugar a todo fermento, instabilidade e qualidades fugidias de uma estética que celebra a diferença, a efemeridade, o espetáculo, a moda e a mercadificação de formas culturais ${ }^{5}$.

Uma contribuição de Harvey (1993, p. 209) fundamental para essa discussão é aquela que aponta a vinculação desses processos com a necessidade - ante as crises que afetam a reprodução ampliada do capital - de acelerar o tempo do giro do capital ${ }^{6}$ no consumo. Para ele, é essa necessidade que tem provocado a mudança de ênfase da produção de bens para a produção de eventos (como é o caso dos espetáculos que tem um tempo de giro quase que instantâneo). Isso decorre do fato de que "[...] quanto mais rápida a recuperação do capital posto em circulação, tanto maior o lucro obtido".

$\mathrm{O}$ efeito consequente disso é a aceleração da atividade econômica e, em consequência, da vida social. $\mathrm{O}$ autor assegura, então, que tais mecanismos podem estar na raiz da rápida penetração capitalista, notada e apontada por Mandel (1982), Jameson (1996, 2001) e Anderson (1999), em diversos setores da produção cultural a partir da década de 1970.

Isso, então, justificaria o comportamento recente da cultura que tende a funcionar de forma simbiótica com a economia. Mesmo porque a produção de mercadorias serve a estilos de vida que são criações da cultura e até mesmo a alta especulação financeira que tem se apoiado em argumentos culturais. A produção cultural, então, se tornou econômica, orientada para a produção de mercadorias (Cevasco, 2010). 
Bolaño (2000), de modo complementar, assevera que o espaço da cultura corresponde a um campo fundamental para a concorrência oligopólica que se estabeleceu no mundo entre os diversos setores da indústria, do comércio e das finanças. Para ele, a cultura, circunscrita nesse complexo, vem cumprindo uma privilegiada função ideológica da qual a publicidade de produtos é apenas um dos aspectos, uma vez que se constitui como espaços de acumulação para certos blocos do capital, valendo-se como parte dos espaços das comunicações e dos canais utilizados para a circulação de diferentes fluxos que irrigam a economia mundial: fluxos de mercadoria, dinheiro, informação e trabalho, já que pelos canais “[...] onde circula o capital circulam também os objetos culturais" (p. 57-58).

Para Ianni, a cultura do capitalismo seculariza a produção cultural com o fim último de torná-la mercadoria, já que é uma exigência da racionalização formal, pragmática, definida em fins e meios objetivos, imediatos e, por isso, esvaziada de valores gerais e particulares.

Não obstante, ainda conforme Ianni (1997), o que está em curso é, pois, um novo ciclo de ocidentalização da vida. Esse novo ciclo recoloca o problema da mundialização da indústria cultural ${ }^{7}$, da expansão dos meios de comunicação de massa e o desenvolvimento de uma cultura particular cujas características sejam capazes de mobilizar povos, nações e continentes.

\section{ESPORTE, ECONOMIA E MERCADO}

A sociedade capitalista vem transformando o esporte, desde o século XX, tal qual grande parte de seus bens culturais, em um setor economicamente dinâmico e altamente rentável.

As práticas esportivas, nesse sentido e contexto, vêm se distanciando, cada vez mais, de sua feição aristocrático-elitista originária para conformar uma lógica mercantil que tende para a valorização do espetáculo, a apropriação/veiculação de signos da indústria de entretenimento e a popularização/ massificação da atividade esportiva ${ }^{8}$ (Proni, 1998).

Foi, então, nesse contexto, que a mercantilização e a espetacularização do fenômeno esportivo foram colocadas em marcha. Para Brohm (1982) e Proni (1998), a ação do mercado publicitário e da mídia especializada no assunto acabou por revolucionar o campo esportivo a partir de novos padrões de relacionamento entre esporte-espetáculo, televisão e marketing esportivo.

Assim, de acordo com a avaliação de Ouriques (2014), o esporte moderno entrou - definitivamente - no circuito mundial de produção e reprodução do capital. Por isso, conforme Brohm (1982), esse fenômeno social, como uma nova esfera do mundo dos negócios, passou a constituir um setor de produção comercial totalmente integrado às leis socioeconômicas que regem o modo de produção capitalista.

Ademais, ainda na análise de Ouriques (2014), como em qualquer indústria, o esporte passou, enquanto mecanismo catalisador, a interagir com vários setores produtivos do mundo capitalista que, não obstante, dele precisa para gerar lucros e potencializar acúmulos.

Para tanto, seu processo de produção, cuja matriz de funcionamento está assentada na lógica comercial, vem buscando ampliar a produção e diversificar o consumo esportivo. Fato que ocorre intimamente relacionado à "[...] criação, destruição e recriação de modelos de saúde, de atletas vitoriosos, ou de distinção social e pessoal que caracterizam a ação dos principais canais da mídia [...]" os quais guardam "[...] relação com a lógica de produção e comercialização de eventos esportivos" (Giovanni, 2005, p. 154).

Para Proni (1998), esse processo de diversificação do consumo está associado a três esferas interdependentes, isto é, ao consumo de bens, de serviços e de espetáculos. A primeira envolve os mercados de artigos e equipamentos esportivos que se desenvolvem com as práticas esportivas amadoras e informais, bem como com a expansão da indústria esportiva e a conversão das estrelas do esporte em modelos de saúde, vigor, sucesso e realização pessoal e, ainda, através do consumo de um estilo de vida esportivo. A segunda, a de serviços, engloba a demanda por iniciação e supervisão esportiva, bem como a 'necessidade' de produção de um corpo modelado. A última, relacionada ao consumo de espetáculos, relaciona-se com a cobertura de 
eventos esportivos que vem se configurando como uma das principais opções de entretenimento (Proni, 1998).

Sobre essa última esfera, é importante apontar - ademais - que foi exatamente a aproximação entre esporte, economia e mercado que forjou aquilo que conhecemos hoje como espetáculo esportivo. Um fenômeno multifacetado e de alta significação simbólica (Pilatti, 2006) que mobiliza atletas, equipes esportivas profissionais, trabalhadores de diversos setores, corporações e entidades empresariais de administração esportiva, além de grande público consumidor, em especial, telespectadores, que acompanha ou assiste a cobertura esportiva [ao vivo] por meio de variados canais de mídia. Por isso, sua realização exige um complexo planejamento e organização, bem como uma eficiente gestão empresarial e um alto controle operacional.

Tais espetáculos, por seus traços, na avaliação de Brohm (1982), podem ser considerados - ainda - como caravanas publicitárias ambulantes. Essas caravanas resultam, então, de um processo de industrialização capitalista do esporte de massa que congrega interesses financeiros e publicitários, ingerência massiva da mídia televisiva e, também, intervenção competitiva de organismos públicos ou privados.

Imbricado nisso está a mercantilização de serviços, de equipamentos, de tecnologias, de marcas, de eventos, assim como a formatação de redes de difusão (canais de TV, jornais, revistas, internet, etc.) e a busca por patrocínios, anunciantes e [compulsivos] consumidores. O resultado é a construção de verdadeiros conglomerados empresariais capazes de transformar o esporte em polo integrador de tecnologia e inovação (Pilatti, 2006).

O esporte de rendimento, nesse cenário, funciona, pois, como o motor do sistema esportivo comercial, uma espécie de mola propulsora ou centro de gravidade (Brohm, 1982) em torno do qual se organiza uma cadeia produtiva ampla e ávida por novos nichos de consumo. Por isso, com a ajuda de novas tecnologias, reinventase, permanentemente, incrementando "velhas" formas de esporte e alimentando "novas" modalidades nichos da programação do lazer, disputados pelas grandes corporações de mídia que alimentam os segmentos do turismo, da publicidade, de equipamentos diversos, de roupas, de games e, inclusive, de alimentação (Kearney, 2003).

A expansão e veiculação do esporte como um elemento da cultura de massa, produzido para e pela exploração dos meios de comunicação, viabilizaram, conforme Athayde (2014), o advento de um paradigma comercial que atualmente tem caracterizado o setor. Esse paradigma, por sua vez, vem produzindo um determinado esporte que, não despretensiosamente, está assentado numa lógica de mercado voltada à comercialização desse fenômeno e, também, de outros produtos que dele se utiliza para penetrar espaços e explorar novos nichos de consumo.

Tais elementos, apresentados até aqui, são elucidativos e emblemáticos da subordinação e sujeição do esporte à forma mercadoria e, consequentemente, a um tipo de comercialização vinculada, sobretudo, à produção espetacularizada do fenômeno esportivo 9 (Proni, 1998; Giovanni, 2005; Athayde, 2014).

Para avalizar tais processos, o modelo de produção comercial do esporte tem colocado às instituições esportivas - especialmente aos clubes que, não por acaso, constitui a célula básica do tecido esportivo - o papel e o desafio de produzir, em quantidade e qualidade cada vez maior, campeões e esportistas capazes de registrar, progressivamente, elevados níveis de produtividade esportiva, isto é, altos índices de performance esportiva (Brohm, 1982).

Logo, o espetáculo, os esportistas, bem como suas marcas, seus recordes e suas competências, produzidas para serem comercializadas e, por isso, inscritas no âmbito das mercadorias, acabam, como resultados de um determinado processo de produção, integrados, subsumidos e submetidos ao capital.

Assim, a aproximação do esporte à economia de mercado aponta uma visceral e orgânica vinculação entre o esporte e o modo de produção capitalista. Fato que ocorre pela via da mercadorização e comodificação da performance esportiva que, não obstante, tem sido produzida enquanto um produto, um artigo ou mesmo uma mercadoria. 
Ademais, tais considerações indicam o movimento de sujeição do esporte ao modo de produção capitalista, ou, em outros termos, de produção de mercadorias, de valores de troca. Isso ocorre uma vez que o processo de produção do esporte, ao produzir determinadas mercadorias - marcas, recordes, competências, esportistas, espetáculos - por meio do trabalho assalariado com o fim de realizar ganhos e valorizar o capital acaba por imiscuir definitiva e deliberadamente o esporte no circuito de valorização do capital.

Essa articulação entre esporte e economia - indicadora da participação do esporte no circuito do capital - ou, como quis Harvey (1993), de modo geral, entre cultura e economia - verificada, sobretudo, a partir da década de 1970 - tem relação com as crises que acometem e afetam a reprodução ampliada do capital.

Para isso, o que está colocado são a produção e o consumo de um esporte espetacularizado que, não obstante, resulta de processos produtivos que influi e cria um público ávido, sensível e capaz de fruição esportiva ao passo que é, por ele, influenciado. Dessa maneira, a produção do esporte espetacularizado não cria apenas uma série de mercadorias e/ou uma cadeia produtiva do esporte, mas também um conjunto de sujeitos capazes de consumir tais produtos.

Bourg e Gouguet (2005), avaliando a natureza do mercado esportivo, informam sobre uma cadeia produtiva que envolve produtos, imagens, capitais e modelos de consumo que se espalham por todos os continentes. Calçados fabricados em Taiwan, bolsas no Paquistão e raquetes na Coréia do Sul, por exemplo, são comercializados em todo o globo - pretensamente - sob marcas americanas, europeias e japonesas. Imagens dos Jogos Olímpicos ou da Copa do Mundo de futebol são vendidas no mundo inteiro. Milhares de esportistas, como mercadorias e produtos esportivos altamente valorizados, emigram para fora de seus domicílios e de suas fronteiras e centenas de competições são tornadas como espetáculos em escala planetária.

Tais aspectos indicam, em última instância, o nível de aproximação e integração do esporte ao modo de produção e valorização do capital. Além disso, permite depreender e confirmar a pujança da "atividade econômica" no setor.

\section{ConsideraÇões FinAis}

Esse texto buscou discutir e problematizar sobre a aproximação/imbricação entre a cultura - e o esporte como um bem cultural, o mercado e a economia no âmbito do capitalismo tardio. Para tanto, num primeiro momento, procurou-se refletir sobre os processos que atravessam o desenvolvimento da cultura no contexto do capitalismo contemporâneo. Em seguida, discorreu-se sobre os níveis de aprofundamento, desdobramento e integração entre esporte e economia de mercado. Desses dois "momentos" é fundamental destacar os processos de fusão entre cultura, economia e mercado.

Ademais, cabe assinalar que o regime de acumulação flexível, implementado, sobretudo a partir de 1970, corresponde, nessa quadra histórica, ao principal artífice de uma lógica cultural assentada numa estética da diferença, da efemeridade, do espetáculo, da moda e da mercadificação da produção cultural. Uma estética comprometida com os esforços para acelerar o giro do capital pela via da produção de eventos que, não obstante, está vinculada à necessidade de indução de necessidades, bem como de estancar as crises que assolam a reprodução ampliada do capital.

A produção de commodities culturais, como a lógica cultural do capitalismo tardio, está submetida, então, à produção de mercadorias em geral e expressa, pois, a associação entre economia, cultura e mercado. Nesses termos, os bens culturais seguem como uma evidente expressão do capitalismo de nossos dias. Por isso, a cultura passa a operar como base (estrutura), além de cumprir seu papel como superestrutura. Ou seja, ela segue produzindo sentidos - especialmente como uma espécie de treinamento para o consumo massificado - e, além disso, passa a gerar lucros e ampliar o capital pela via da integração progressiva ao sistema de mercantificação de seus bens, tais quais as demais áreas produtivas.

Assim, como apresentado, o esporte, como um bem cultural privilegiado, não fica imune a tais processos. Pelo contrário, seu desenvolvimento e organização - conformando um paradigma comercial - acabam por 
distanciar, cada vez mais, de seu caráter aristocrático-elitista que marcou seu nascimento, para acomodar interesses comerciais voltados à espetacularização do fenômeno esportivo, à incorporação de signos e valores da indústria cultural de entretenimento, bem como a massificação do consumo esportivo via televisão.

Nesses termos, a aproximação entre cultura esportiva e economia de mercado, implementada a partir dos anos 1970, viabilizou processos amplos de mercantilização e espetacularização da atividade esportiva. Tais processos só foram possíveis graças à ação deliberada do mercado publicitário, da mídia especializada no assunto que, não por acaso, remodelaram as relações entre esporte, espetáculo, televisão e marketing esportivo, influenciando, por conseguinte, as ações do próprio setor esportivo.

Como uma nova esfera do mundo dos negócios, um espaço de acumulação para certos blocos do capital, o esporte passou a interagir com vários setores produtivos. Nessa direção, os grandes espetáculos esportivos, como uma mercadoria especial que exige alta organização e complexo planejamento, além de eficiente gestão empresarial, passaram a avalizar, divulgar e propagandear outras mercadorias. Servindo, portanto, como veículo de outros produtos, ou mesmos, como caravanas publicitárias privilegiadas.

Ademais, a integração do esporte à economia de mercado levou a amplos processos de ampliação e diversificação da produção e do consumo que se assentam na mercadificação e comodificação da performance esportiva. O que, por seu turno, tem resultado em conglomerados empresariais que se organizam como polo integrador de tecnologia e inovação. Isto é, nichos da programação do lazer - altamente informatizados que são apropriados e disputados pela mídia e por setores privatistas e privatizantes.

Tais questões são, pois, elucidativas e emblemáticas dos processos de subordinação e sujeição da cultura [de modo geral] e do esporte [de maneira particular] à forma mercadoria. O que assinala a necessidade de pesquisa [de natureza empírica], de investigação cuidadosa e de análise crítica e aprofundada com vistas a tornar inteligível o que vem sendo a cultura e, particularmente, o esporte nesse capitalismo contemporâneo.

\section{REFERÊNCIAS}

Anderson, P. (1999). As origens da pós-modernidade. Rio de Janeiro: Jorge Zahar Ed.

Athayde, P. F. A. (2014). O ornitorrinco de chuteiras: determinantes da politica de esporte do governo Lula e suas implicaçôes sociais. (Tese de Doutorado). Universidade de Brasília, Departamento de Serviço Social, Brasília, Brasil.

Bolaño, C. (2000). Indústria cultural, informação e capitalismo. São Paulo: Hucitec.

Bourg, J-F., y Gouguet, J-J. (2005). Economia do esporte. Bauru: Edusc.

Brohm, J-M. (1982). Sociologia Politica del deporte. Cidad del México: Fondo de Cultura Económica.

Canclini, N. G. (1983). Políticas culturais na América Latina. Novos Estudos CEBRAP, 2(2), 39-51.

Castellani Filho, L. (2013). Educação física, esporte e lazer: reflexões nada aleatórias. Campinas: Autores Associados.

Cevasco, M. E. (2010). O sentido da crítica cultural. Revista Cult, 1(1), s/p. Recuperado de https://revistacult.uol.c om.br/home/o-sentido-da-critica-cultural/

Giovanni, G. (2005). Mercantilização das práticas corporais: o esporte na sociedade de consumo de massa. Revista Gestão Industrial, 1(1), 146-155.

Gonçalves, M. A. (1997, novembro 02). Intercâmbio aproxima países e anuncia 'cultura global'. Folha de São Paulo, Caderno Especial - Globalização-10.

Gramsci, A. (2011). Cadernos do cárcere. v. 3 - Maquiavel. notas sobre o estado e a politica. Rio de Janeiro: Civilização Brasileira.

Harvey, D. (1993). A condição pós-moderna: uma pesquisa sobre as origens da mudança cultural. São Paulo: Edições Loyola.

Harvey, D. (2011). O enigma do capital: e as crises do capitalismo. São Paulo: Boitempo.

Heller, A. (2004) O cotidiano e a história. São Paulo: Paz e Terra. 
Hobsbawm, E. (1997). Era dos extremos: o breve século XX (1914-1991). 2. ed. São Paulo: Companhia das Letras. Ianni, O. (1997). A sociedade global. 5. ed. Rio de Janeiro: Civilização Brasileira.

Jameson, F. (1996). Pós-modernismo: a lógica cultural do capitalismo tardio. São Paulo: Editora Ática.

Jameson, F. (2001). A cultura do dinheiro: ensaios sobre a globalização. Petrópolis: Vozes.

Kearney, A. T. (2003). O jogo está começando. HSM Management, 39(1), 37-46.

Mandel, E. (1982). O capitalismo tardio. São Paulo: Abril Cultural.

Marx, K. (1982). Introdução [à Crítica da economia política]. In: Marx, K.. Para a crítica da economia política [e outros escritos]. São Paulo: Abril Cultural.

Ouriques, N. (2014). Megaeventos no Brasil, o desenvolvimento do subdesenvolvimento e o assalto ao Estado. En Capela, P., y Tavares, E. (Eds.), Megaeventos esportivos: suas consequências, impactos e legados para a América Latina. Florianópolis: Insular.

Netto, J. P. (1996). Transformações societárias e serviço social: notas para uma análise prospectiva da profissão no Brasil. Serviço Social \& Sociedade, 17(50), 87-132.

Pilatti, L. A. (2006). A lógica da produção do espetáculo: o esporte inserido na indústria do entretenimento. Revista de Economia Politica de las Tecnologías de la Información e Comunicación, 8(2).

Portelli, H. (1977). Gramsci e o Bloco Histórico. Rio de Janeiro: Paz e Terra.

Proni, M. W. (1998). Esporte-espetáculo e futebol-empresa (Tese de Doutorado). Universidade Estadual de Campinas, Faculdade de Educação Física, Campinas, Brasil.

Simionatto, I. (2003). Cultura no capitalismo globalizado. Novos consensos e novas subalternidades. En Coutinho, C. N., y Teixeira, A. P. (Eds.). Ler Gramsci, entender a realidade. Rio de Janeiro: Civilização Brasileira.

Williams, R. (2000). Cultura. 2. ed. São Paulo: Paz e Terra.

\section{Notas}

1 Embora a expressão cultura acomode entendimentos e definições diversas, esse texto trabalha com a ideia de cultura como um elemento constitutivo da ordem social vigente. Para tanto, recorre-se a Williams (2000, p. 12) quando afirma que “[...] a 'prática cultural' e a 'produção cultural' não procedem apenas de uma ordem social diversamente constituída, mas são elementos importantes em sua constituição”. É exatamente por isso que as manifestações culturais não podem ser consideradas secundárias no processo de apreensão da ordem social, uma vez que são constitutivas e integrantes da mesma. Para o autor, a cultura também é um sistema de significações mediante o qual necessariamente uma dada ordem social é comunicada, reproduzida, vivenciada e estudada

2 Um momento marcado pela explosão tecnológica da eletrônica moderna e seu papel como principal fonte de lucro e inovação; predomínio empresarial das corporações multinacionais, deslocando as operações industriais para os países distantes com salários baixos; imenso crescimento da especulação internacional; e ascensão dos conglomerados de comunicação com um poder sem precedentes sobre toda a mídia que ultrapassa fronteiras (Anderson, 1999).

3 Buscando demonstrar tal questão, Jameson (2001) argumenta que os filmes e a televisão americanos são tanto base quanto superestrutura, tanto econômico quanto cultura, respondendo por um dos principais produtos de exportação dos Estados Unidos, ou seja, uma fonte de renda e de lucros. Ainda nessa direção, o autor assegura que, não por acaso, há uma insistência norte-americana para a abertura das barreiras de quotas de cinema em países estrangeiros. Desse modo, não se trata de uma excentricidade cultural norte-americana, mas antes, uma necessidade comercial.

4 A acumulação flexível pode ser caracterizada pelo surgimento de setores produtivos inteiramente novos, além de novas maneiras de fornecimento de serviços financeiros, mercados e, principalmente, taxas altamente intensificadas de inovação comercial, tecnológica e organizacional. Ademais, envolve, rápidas mudanças nos padrões de desenvolvimento desigual, tanto entre setores como entre regiões geográficas, bem como conjuntos industriais completamente novos em regiões marcadas até então por subdesenvolvimento (Harvey, 1993).

5 Tais mudanças, ainda para Harvey (1993), associadas a alterações na produção, na reunião de informações e no financiamento parece estar na base do crescimento do setor de serviços a partir de 1970.

6 O tempo de giro de capital, conforme o próprio Harvey (1993), corresponde ao tempo de produção associado ao de circulação da troca. 
7 A ideia de Indústria Cultural é desenvolvida por Theodor Adorno e Max Horkheimer - integrantes da Escola de Frankfurt. Para eles, essa expressão se refere à produção cultural no capitalismo como produção de mercadorias. Nessa direção, a produção cultural e intelectual foi orientada pela possibilidade de consumo mercadológico, viabilizando a lucratividade do sistema. Ademais, a Indústria Cultural, na concepção desses autores, exerce uma função fundamental de preservar, reproduzir e renovar o capitalismo, já que atua na formação de um público consumidor.

8 O que ocorre especialmente a partir da inserção da televisão nos processos de comercialização e distribuição do esporte enquanto mais um produto formatado pelo audiovisual.

9 Aspecto que encontra acordo com as observações de Marx (1982) segundo as quais a produção e o consumo se relacionam e se determinam desenfreadamente. Para Marx (1982), a produção é o objeto exterior, material, do consumo e o consumo, o objeto ideal da produção. Cada um dos termos não se limita a ser imediatamente o outro, nem o mediador do outro, mas, mais do que isso, ao realizar-se, cria o outro, realiza-se sob a forma do outro. Isso posto, explica Marx por analogia, o objeto da arte - e analogamente, qualquer outro produto - cria um público sensível à arte e capaz de fruição estética. Deste modo, a produção não cria só um objeto para o sujeito; cria também um sujeito para o objeto. 